\title{
CORRECTION
}

\section{Correction to: Anemia and PET imaging}

\author{
Ismet Sarikaya ${ }^{1} \cdot$ Ali Baqer $^{2} \cdot$ Ali Sarikaya ${ }^{3}$
}

Published online: 23 August 2021

(c) Italian Association of Nuclear Medicine and Molecular Imaging 2021

\section{Correction to: Clinical and Translational Imaging https://doi.org/10.1007/s40336-021-00442-z}

Publisher's Note Springer Nature remains neutral with regard to jurisdictional claims in published maps and institutional affiliations.

In this article the reference numbers in the figure captions 2 , 6 and 7 were incorrect.

In Fig. 2 caption the reference is 41 instead of 28 . In Fig. 6 caption the reference is 59 instead of 46. In Fig. 7 caption the reference is 61 instead of 48 . The original article has been corrected.

The original article can be found online at https://doi.org/10.1007/ s40336-021-00442-z.

Ismet Sarikaya

isarikaya99@yahoo.com

1 Department of Nuclear Medicine, Kuwait University Faculty of Medicine and Mubarak Al-Kabeer Hospital, PO Box 24923, 13110 Safat, Kuwait

2 Department of Nuclear Medicine, Mubarak Al-Kabeer Hospital, Jabriya, Kuwait

3 Department of Nuclear Medicine, Trakya University Faculty of Medicine, Edirne, Turkey 